\title{
Simultaneous bladder rupture with obstetrics anal sphincter injury following forceps application: a case report and review of literature
}

\author{
Kishore Chandra Mahapatra, Santosh Kumar Dora*, Atal Bihari Dandapat, Bulu Naik, \\ Debashish Dash, Snehadarshini Karanth
}

Department of Obstetrics and Gynecology, VIMSAR, Burla, Odisha, India

Received: 02 April 2017

Revised: 15 April 2017

Accepted: 02 May 2017

\section{*Correspondence:}

Dr. Santosh Kumar Dora,

E-mail: santoshdora1@gmail.com

Copyright: () the author(s), publisher and licensee Medip Academy. This is an open-access article distributed under the terms of the Creative Commons Attribution Non-Commercial License, which permits unrestricted non-commercial use, distribution, and reproduction in any medium, provided the original work is properly cited.

\begin{abstract}
In the modern era use of instrumental delivery is on a declining trend. Due to increase morbidity associated with forcep applications most women in developing countries preferred emergency caesarean section over instrumental delivery. But in country like India instrumental delivery is still preferable over caesarean section in many situations. We report a case that was referred from a peripheral hospital with simultaneous bladder and anal sphincter injury to our hospital. She was managed by a multidisciplinary team including urologist, surgeon and gynaecologist. Such type of case is very rare in modern era. To prevent such complications prerequisite for forcep application must be fulfilled. So that bladder injury, urinary fistula, anal incontinence and fetal complication can be avoided.
\end{abstract}

Keywords: Bladder rupture, Forceps application, Obstetrics anal sphincter injury (OASIS), Obstetrics forceps

\section{INTRODUCTION}

Though the use of obstetrics forceps has been reduced in the era of modern obstetrics due to the fear of maternal and neonatal morbidity but, certain difficult situations may prompt physicians to use them. Some conditions like maternal exhaustion, prolonged second stage, non assuring fetal heart rate, forceps are required for the next step of management. In most cases, forceps are not used if an emergency caesarean section can be conducted, which is not always feasible in peripheral hospitals of developing countries like India.

Forceps delivery is an established risk factor influencing genital tract injuries, which is reported by the systemic review of 14 studies. ${ }^{1}$ The forceps use predisposes women to different short-term and long-term morbidities in the form of perineal injuries of 3rd degree and 4th degree, cervical tears, uterine rupture, bladder injury, vesico-vaginal fistula and recto-vaginal fistula. ${ }^{2}$ In literature there is isolated case of either bladder injury or perineal injuries are there, but in a patients simultaneous presence of both is very rare and one of the dreaded complication of instrumental delivery. We report one of such case of simultaneous bladder injury and 4th degree perineal tear in a woman following forceps application, referred from a peripheral hospital with emphasis on its management.

\section{CASE REPORT}

A 20-years-old woman, primi para with one living issue, on her 1st puerperal day admitted to our hospital through emergency service with complain of bleeding per vaginum and continuous dribbling of urine following delivery. On review of referral slip it was revealed that, she delivered on the same day in a peripheral hospital by the use of outlet forceps for prolonged labour, following which there was traumatic PPH due to $4^{\text {th }}$ degree perineal tear which had been repaired and the patient was referred 
with a vaginal pack in situ. On examination patient was conscious, oriented with severe degree of pallor. There was tachycardia with normal blood pressure. On abdominal examination uterus was well retracted and rest of the abdomen was normal. On vaginal exploration following removal of pack revealed, midline anterior vaginal wall tear involving the posterior wall of bladder with a rent through which the Foleys bulb was felt. Also, there was repaired 4th degree perineal tear as confirmed by per rectal examination. There was no active bleeding and cervix was normal.

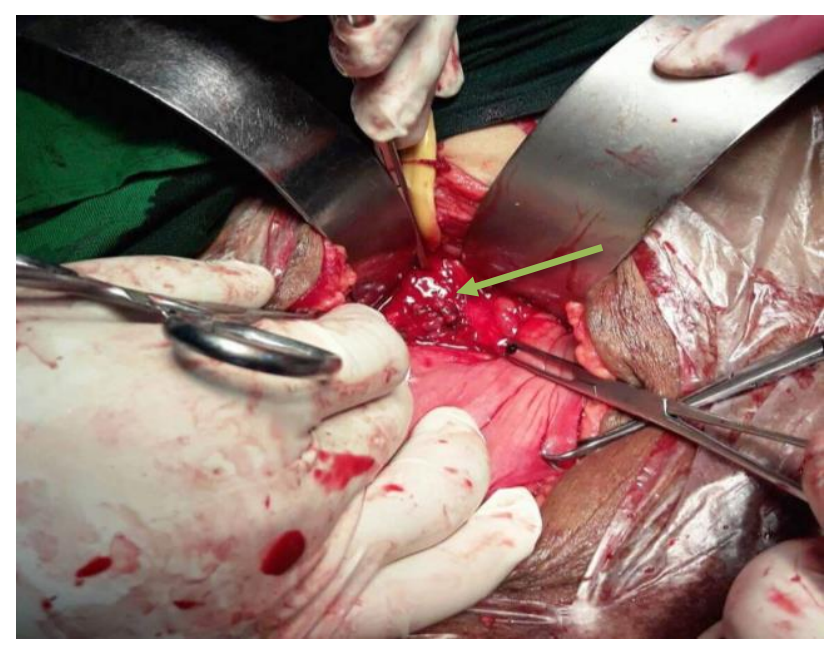

Figure 1: Bladder injury repaired followed by suprapubic urinary catheter insertion (marked with an arrow).

After urologist consultation bladder repair was planned through abdominal route after two unit of blood transfusion. On laparotomy bladder was identified, cystostomy made. A lacerated injury found on the posterior wall of bladder on intertrigonal region extending upto bladder neck. There was a ragged lacerated vaginal margin with blood clots. Both the ureteric orifices identified and cannulated with infant feeding tube with free urine drainage. The injury site repaired with vicryl 4-0 with proper hemostasis taking care of the ureteric orifices (Figure 1). Suprapubic catheter was placed. Cystostomy closure was done. A perivescical drain was placed and abdomen closed in layers. Postoperatively Solifenacin $10 \mathrm{mg}$ was given for few days with higher antibiotics.

Patient had satisfactory post-operative recovery. She was advised liquid and semisolid diets for few days along with laxatives. Catheter was removed after 21 days. Now the patient is doing well with normal bladder and bowel habits.

\section{DISCUSSION}

In Royal college of Obstetricians and Gynecologists (RCOG) consultant conference, operative vaginal delivery rate of $10.5 \%$ was reported (range 4-20\%) while the consensus emphasize to lower it to average of $8.5 \%$ (range $5-15 \%$ ). ${ }^{3}$ The incidence of forceps delivery is $0.8 \%$ according to ACOG 2011 guideline. ${ }^{4}$ Close proximity of urogenital system in female increases the possibility of obstetrics injury while instrumental delivery. Trigon of bladder rests on anterior vaginal fornix and base rests on lower uterine segment and cervix. It may be injured during obstetric procedures. Intra peritoneal urinary bladder wall rupture usually associated with rupture uterus during labor which has been reported by many authors, but bladder rupture following vaginal delivery is rare. ${ }^{5,6}$ Bladder injury is seen commonly during delivery if bladder emptying was not done before. In present case we don't have information regarding whether forcep was applied after the bladder evacuation or not resulting in bladder rupture. Rupture of bladder can also occur in case of over distended bladder during precipitated labor. ${ }^{7}$

Sandler et al has described five types of bladder injuries with conventional cystography such as simple bladder contusion, intra peritoneal rupture, interstitial bladder injury, extra peritoneal bladder rupture and combination of intra and extra peritoneal bladder rupture. ${ }^{8}$ Intra peritoneal bladder injury results due to sudden increase in pressure within the distended bladder due to external force/pressure. It demonstrates extra luminal contrast extravasation to intra peritoneal cavity within bowel loops in cystography. Extra peritoneal bladder wall rupture is the most common type of injury due to trauma and caused due to penetrating or blunt trauma. Contrast extravasation is confined to perivesical and extra peritoneal space. The clinical diagnosis of extra peritoneal bladder rupture is difficult and requires a high index of suspicion. Bladder wall contusion and interstitial bladder wall injury are managed conservatively. Intra peritoneal and combined types of bladder injuries are managed by surgical repair. Extra peritoneal bladder rupture is usually managed by prolonged catheterization and antibiotics. CT cystography can be done in patient even with impaired renal functions and is the investigation of choice for diagnosis of bladder injuries. Our patient had both intra and extra peritoneal bladder injury which was managed surgically.

Fetal head compresses the distended urinary bladder over pelvic brim and symphysis pubis during uterine contraction and results pressure necrosis and perforation of urinary bladder wall. Thus, emptying of urinary bladder before delivery, postpartum and in puerperal state is to be encouraged strictly to prevent bladder wall rupture. Clinical signs and symptoms includes anuria, oliguria, haematuria, vague abdominal pain and ascites along with abnormal blood biochemistry highly suggestive of renal failure, should alert the clinician about the possibility of a urinary bladder rupture

OASIS is a major concern in forceps delivery. In order to minimize risk of tears from instrumental deliveries, it is recommended that the traction is performed to maintain 
the flexion of fetal head in the direction of the pelvic floor. A survey showed that most obstetricians in North America have abandoned rotational instrumental delivery in favour of caesarean section due to increase of OASIS. ${ }^{9}$ In Australia, obstetricians prefer using a vacuum extractor for rotational instrumental delivery. This has reinforced the opinion of some obstetricians that rotational deliveries of more than $45^{\circ}$ are likely to be abandoned. ${ }^{10}$ All women undergoing instrumental vaginal delivery are at risk of sustaining anal sphincter injury or isolated rectal buttonhole tears. They should therefore be examined systematically; including a digital rectal examination, to assess the severity of damage, particularly prior to suturing. Liberal episiotomy, good perineal support and right direction of traction will avoid OASIS. ${ }^{11}$

Perineal trauma is an unfortunate outcome of vaginal delivery. OASIS and bladder injury have short and long term implications. These are perineal pain, dyspareunia, urinary fistula and anal dysfunction which can lead to psychological, social and marital problems and implication regarding future delivery. Although obstetrics anal sphincter injury can never be eliminated, but bladder injury which is a rarest complication, that can be reduced by improving practice, meeting the criteria for forcep application, training and provision of high quality multidisciplinary care in order to reduce long-term morbidity.

Funding: No funding sources

Conflict of interest: None declared

Ethical approval: Not required

\section{REFERENCES}

1. Adams EJ, Bricker L, Richmond DH, Neilson JP. Systemic review of third degree tears: risk factors. Int Urogynecol J Pelvic Floor Dysfunct. 2001;12:12.

2. Mahony R, O' Herlihy C. Recent impact of anal sphincter injury on overall caesarean section incidence. Aus NZ J Obstet Gynaecol. 2006;46:2024.

3. Johnson R. Advances in assisted vaginal delivery with vacuum extractor. Bonnar J (Ed). Recent advances in obstetrics and gynecology. Edinburgh: Churchill Livingstone;1998:125-39.

4. American College of Obstetricians and Gynecologists: Operative vaginal delivery. Practice Bulletin No. 17, June 2000, Reaffirmed 2012.

5. Atug F, Akay F, Aflay U, Sahin H, Yalinkaya A. Delivery of dead fetus from inside urinary bladder with uterine perforation: Case report and review of literature. Urology. 2005;65:797.

6. Alonso AH, Fernández ER, Sánchez JP, Escudero RM, Jiménez JT, García EL et al. Giant retroperitoneal abscess caused by extraperitoneal bladder rupture after instrumental vaginal delivery. Eur J Obstet Gynecol Reprod Biol. 2011;158:368- 9.

7. Ekuma- Nkama EN, Garg VK, Barayan S. Spontaneous rupture of bladder in a primipara. Ann Saudi Med. 1997;17:646- 7.

8. Sandler CM, Hall JT, Rodriguez MB, Corriere JN Jr. Bladder injury in blunt pelvic trauma. Radiology. 1986;158:633- 8 .

9. Bofill JA, Rust OA, Perry KG, Roberts WE, Martin RW, Morrison JC. Operative vaginal delivery: a survey of fellows of ACOG. Obstet Gynecol. 1996;(88):1007-10.

10. Johanson RB, Menon BK. Vacuum extraction versus forceps for assisted vaginal delivery, Cochrane Database Syst Rev. 2000;(2):CD000224.

11. The Management of Third- and Fourth-Degree Perineal Tears. RCOG June 2015; Green-top Guideline No. 29.

Cite this article as: Mahapatra KC, Dora SK, Dandapat AB, Naik B, Dash D, Karanth S.

Simultaneous bladder rupture with obstetrics anal sphincter injury following forceps application-a case report and review of literature. Int J Reprod Contracept Obstet Gynecol 2017;6:2660-2. 